\title{
Adult lung function and long-term air pollution exposure. ESCAPE: a multicentre cohort study and meta-analysis
}

\author{
Martin Adam ${ }^{1,2,27}$, Tamara Schikowski ${ }^{1,2,3,27}$, Anne Elie Carsin ${ }^{4,27}$, Yutong Cai ${ }^{5}$, Benedicte Jacquemin ${ }^{4,6,7}$, \\ Margaux Sanchez ${ }^{6,7}$, Andrea Vierkötter ${ }^{3}$, Alessandro Marcon ${ }^{8}$, Dirk Keidel ${ }^{1,2}$, Dorothee Sugiri ${ }^{3}$, Zaina Al Kanani ${ }^{5}$, \\ Rachel Nadif ${ }^{6,7}$, Valérie Siroux $x^{9,10}$, Rebecca Hardy ${ }^{11}$, Diana Kuh ${ }^{11}$, Thierry Rochat ${ }^{12}$, Pierre-Olivier Bridevaux ${ }^{12}$, \\ Marloes Eeftens ${ }^{1,2,13}$, Ming-Yi Tsai ${ }^{1,2}$, Simona Villani ${ }^{14}$, Harish Chandra Phuleria ${ }^{1,2}$, Matthias Birk ${ }^{15}$, \\ Josef Cyrys ${ }^{15,16}$, Marta Cirach ${ }^{4}$, Audrey de Nazelle ${ }^{17}$, Mark J. Nieuwenhuijsen ${ }^{4}$, Bertil Forsberg ${ }^{18}$, Kees de \\ Hoogh $^{5}$, Christophe Declerq ${ }^{+19}$, Roberto Bono ${ }^{20}$, Pavilio Piccioni ${ }^{21}$, Ulrich Quass ${ }^{22}$, Joachim Heinrich ${ }^{15}$, \\ Deborah Jarvis ${ }^{5,23}$, Isabelle Pin ${ }^{9,10,24}$, Rob Beelen ${ }^{13}$, Gerard Hoek ${ }^{13}$, Bert Brunekreef ${ }^{13,25}$, Christian Schindler ${ }^{1,2}$, \\ Jordi Sunyer ${ }^{4,28}$, Úrsula Krämer ${ }^{3,28}$, Francine Kauffmann ${ }^{6,28}$, Anna L. Hansell ${ }^{5,26,28}$, Nino Künzli' ${ }^{1,2,28}$ and \\ Nicole Probst-Hensch ${ }^{1,2,28}$
}

\begin{abstract}
Affiliations: ${ }^{1}$ Swiss Tropical and Public Health Institute, Basel. ${ }^{2}$ University of Basel, Basel, and ${ }^{12}$ Division of Pulmonary Medicine, University Hospitals of Geneva, Geneva, Switzerland. ${ }^{3}$ Leibniz Research Institute for Environmental Medicine (IUF), Düsseldorf, and ${ }^{15} \mathrm{Helmholtz} \mathrm{Zentrum,} \mathrm{München} \mathrm{and} \mathrm{German} \mathrm{Research} \mathrm{Centre}$ for Environmental Health, Institute of Epidemiology I, Neuherberg. ${ }^{16}$ Environmental Science Center, University Augsburg. Augsburg, and ${ }^{22}$ Air Quality and Sustainable Nanotechnology, IUTA Institut für Energie- und Umwelttechnik e.V., Duisburg, Germany. ${ }^{4}$ Centre for Research in Environmental Epidemiology (CREAL), Barcelona, Spain. ${ }^{5}$ MRC-PHE Centre for Environment and Health, Dept of Epidemiology and Biostatistics, School of Public Health, Imperial College London, London, ${ }^{11}$ MRC University Unit for Lifelong Health and Ageing, University College London, London, ${ }^{17}$ Centre for Environmental Policy, Imperial College London, London, ${ }^{23}$ Dept of Respiratory Epidemiology and Public Health, National Heart and Lung Institute, Imperial College London, London, and ${ }^{26}$ Public Health and Primary Care Directorate, Imperial College Healthcare NHS Trust, London, UK. 'Inserm, Centre for Research in Epidemiology and Population Health (CESP), U1018, Respiratory and Environmental Epidemiology Team, Villejuif. ${ }^{7}$ Univ. Paris-Sud, UMRS 1018, Villejuif, ${ }^{9}$ Inserm U823, Environmental Epidemiology Applied to Reproduction and Respiratory Health Team, Grenoble. ${ }^{10}$ Univ. Joseph Fourier, Grenoble, ${ }^{19}$ French Institute for Public Health Surveillance, Saint-Maurice, and ${ }^{24}$ Pédiatrie, $\mathrm{CHU}$ de Grenoble, La Tronche, France. ${ }^{8}$ Unit of Epidemiology and Medical Statistics, Dept of Public Health and Community Medicine, University of Verona, Verona. ${ }^{14}$ Unit of Biostatistics and Clinical Epidemiology Dept of Public Health, Experimental and Forensic Medicine University of Pavia, Pavia. ${ }^{20}$ Dept of Public Health and Pediatrics, University of Turin, Turin, and ${ }^{21}$ SC Pneumologia CPA ASL 4 Turin, Turin, Italy. ${ }^{13}$ Institute for Risk Assessment Sciences, Utrecht University, Utrecht, and ${ }^{25}$ Julius Center for Health Sciences and Primary Care, University Medical Center Utrecht, Utrecht, The Netherlands. ${ }^{18}$ Environmental and Occupational Medicine, Dept of Public Health and Clinical Medicine, Umeå University, Umeå, Sweden. ${ }^{27}$ These authors contributed equally. ${ }^{28}$ Steering Committee of ESCAPE Work Package 4 on Respiratory Health in Adults.
\end{abstract}

Correspondence: Nicole Probst-Hensch, Head Unit Chronic Disease Epidemiology, Swiss Tropical and Public Health Institute, Socinstrasse 57, P.O. Box, 4002 Basel, Switzerland. E-mail: Nicole.ProbstQunibas.ch

ABSTRACT The chronic impact of ambient air pollutants on lung function in adults is not fully understood. The objective of this study was to investigate the association of long-term exposure to ambient air pollution with lung function in adult participants from five cohorts in the European Study of Cohorts for Air Pollution Effects (ESCAPE).

Residential exposure to nitrogen oxides $\left(\mathrm{NO}_{2}, \mathrm{NO}_{\mathrm{x}}\right)$ and particulate matter (PM) was modelled and traffic indicators were assessed in a standardised manner. The spirometric parameters forced expiratory volume in $1 \mathrm{~s}$ (FEV1) and forced vital capacity (FVC) from 7613 subjects were considered as outcomes. Cohort-specific results were combined using meta-analysis.

We did not observe an association of air pollution with longitudinal change in lung function, but we observed that a $10 \mu \mathrm{g} \cdot \mathrm{m}^{-3}$ increase in $\mathrm{NO}_{2}$ exposure was associated with lower levels of $\mathrm{FEV} 1(-14.0 \mathrm{~mL}$, 95\% CI -25.8 to -2.1$)$ and FVC $(-14.9 \mathrm{~mL}, 95 \% \mathrm{CI}-28.7$ to -1.1$)$. An increase of $10 \mu \mathrm{g} \cdot \mathrm{m}^{-3}$ in PM10, but not other PM metrics (PM2.5, coarse fraction of PM, PM absorbance), was associated with a lower level of FEV1 $(-44.6 \mathrm{~mL}, 95 \% \mathrm{CI}-85.4$ to -3.8$)$ and FVC $(-59.0 \mathrm{~mL}, 95 \% \mathrm{CI}-112.3$ to -5.6$)$. The associations were particularly strong in obese persons.

This study adds to the evidence for an adverse association of ambient air pollution with lung function in adults at very low levels in Europe. function in adults http://ow.ly/A1ssB 


\section{Introduction}

Lung function, specifically forced vital capacity (FVC) and forced expiratory volume in $1 \mathrm{~s}$ (FEV1), are objectively measurable quantitative parameters of respiratory health. It is an early indicator of respiratory and systemic inflammation, and associated with cardiorespiratory morbidity and mortality. Acute effects of air pollution on lung function at levels currently observed in Western Europe at all ages are well established. To what extent long-term exposure to air pollution results in lower lung function remains less clear [1]. Evidence for long-term pollution effects on slowing down lung function growth in children is strong, while data for chronic lung function effects in adults is more limited and mostly restricted to susceptible populations [1-3]. In the largest of the predominantly cross-sectional studies [4-7], FORBES et al. [4] found increases in $10 \mu \mathrm{g} \cdot \mathrm{m}^{-3}$ of particulate matter of size $10 \mu \mathrm{m}$ or less (PM10) associated with a decrease of about $3 \%$ in FEV1. At first spirometry SAPALDIA found an increase of $10 \mu \mathrm{g} \cdot \mathrm{m}^{-3}$ in annual mean concentration of PM10 was associated with 3.4\% lower FVC and 1.6\% lower FEV1 [5]. The SALIA study of females showed negative associations of PM10 concentrations with FEV1 and FVC (5.1\% and 3.7\% respectively, per $7 \mu \mathrm{g} \cdot \mathrm{m}^{-3}$ 5-year annual mean PM10) [7]. The strongest indirect evidence for adverse long-term pollution effects on lung function decline in adults comes from a single follow-up study demonstrating that improvements in PM10 exposure over a period of 11 years attenuated the age-related decrease in respiratory function [8]. A more recent study found cumulative long-term exposure to ambient $\mathrm{PM} 10$ and ozone associated with both FEV1 and FVC decline in an elderly population and suggested an increased susceptibility among frail persons [9]. Statistically significant associations were also reported for $\mathrm{NO}_{2}$ and traffic exposure $[5,7]$.

The ESCAPE project (European Study of Cohorts for Air Pollution Effects) combined data from over 30 cohort studies and modelled home outdoor levels of air pollution in a standardised manner [10]. This paper makes use of five health cohorts with spirometry data, to investigate the association of air pollution with lung function level and age-related decline.

\section{Methods}

\section{Design and participants}

This study is an analysis of cohort data obtained by ESCAPE to investigate the long term effects of exposure to air pollution on respiratory health in Europe and a meta-analysis of the cohort specific results. The present study included five European cohorts/studies from eight countries with information on lung function and the most important potential confounders. The analyses were based on subpopulations from the European Community Respiratory Health Survey (ECRHS), French Epidemiological study on Genetics and Environment of Asthma (EGEA), the National Survey of Health and Development (NSHD), Study on the influence of Air pollution on Lung function, Inflammation and Aging (SALIA) and Swiss Cohort Study on Air Pollution and Lung and Heart Diseases in Adults (SAPALDIA) (online supplementary material (methods: cohorts section) and supplementary table S1). Criteria for inclusion of cohort participants in the present analyses were: age of at least 20 years; pre-bronchodilation spirometry data from two different time points approximately one decade apart (referred to as first and second spirometry, respectively); non-missing information for the primary covariates used in the main models (questionnaire-based variables: age, sex, smoking status, education; measured variables: height and BMI (derived from measured height and weight)); living in cohort areas selected for ESCAPE monitoring campaigns; and successfully assigned home outdoor exposure estimates for $\mathrm{NO}_{2} / \mathrm{NO}_{\mathrm{x}} /$ traffic indicators (referred to as NO-population) and PM metrics (a subsample of the NO population, referred to as PM-population). Of 13259 participants with first and second spirometry living in ESCAPE monitoring

For editorial comments see Eur Respir J 2015; 45: 11-13 [DOI: 10.1183/09031936.00168814].

This article has online supplementary material available from erj.ersjournals.com

Received: July 162014 | Accepted after revision: July 242014 | First published online: Sept 052014

Support statement: The research leading to these results has received funding from the European Community's Seventh Framework Program (FP7/2007-2011) under grant agreement number 211250. Funding details for the individual study cohorts of the ESCAPE project (ECRHS/ECRHS II, EGEA, NHSD, SALIA and SAPALDIA) can be found in the acknowledgements section. The funding source had no role in study design; in the collection, analysis, and interpretation of data; in the writing of the report; and in the decision to submit the paper for publication. The authors had full access to all data and had final responsibility for the decision to submit the paper.

Conflict of interest: Disclosures can be found alongside the online version of this article at erj.ersjournals.com

Copyright CERS 2015. ERJ Open articles are open access and distributed under the terms of the Creative Commons Attribution Non-Commercial Licence 4.0 . 
areas, 7615 and 4233, respectively provided complete datasets towards analysis of $\mathrm{NO}_{2} / \mathrm{NO}_{\mathrm{x}} /$ traffic indicators and PM metrics (supplementary figure S1). All included cohort studies were approved by the institutional medical ethics committees and undertaken in accordance with the Declaration of Helsinki. Each cohort study followed the rules for ethics and data protection set up in the country in which they were based.

\section{Exposure data}

ESCAPE exposure assessment has been described previously, and is based on fully standardised measurement and modelling protocols (www.escapeproject.eu/manuals/) [10-13]. The general concept consisted in the individual assignment of outdoor annual mean concentrations of a pre-defined set of air pollution markers to each participant's residential address.

ESCAPE monitoring campaigns in different study areas between 2008 and 2011 measured $\mathrm{NO}_{2}$ and $\mathrm{NO}_{\mathrm{x}}$ as well as, in a smaller number of areas PM2.5, PM10, the coarse fraction of PM (PM10 minus PM2.5) and light absorbance of PM2.5. Within each study area, concentration levels were monitored at $40\left(\mathrm{NO}_{2}, \mathrm{NO}_{\mathrm{x}}\right)$ or 20 (PM measures) predefined sites during three seasonally distinct 2-week periods [13, 14]. Land use regression (LUR) models were developed to explain the spatial variation of measured annual average air pollutant concentration within each study area. This technique combines measurement data with Geographic Information System (GIS) derived land-use and traffic information to predict annual pollution concentration at sites without measurements and was used to estimate annual pollutant concentrations at each participant's residential address $[10,11]$.

In addition to pollutant concentrations, we also used as indicators of local exposure to traffic related pollutants, traffic intensity at the road nearest to a participant's home and total traffic load on major roads in a $100-\mathrm{m}$ buffer of the home. Traffic measures were often used in other studies as proxies of exposure to near-road pollutants, such as ultrafine particles or NO, which exponentially decay within 100-150 m from the curb side.

To address the time discrepancy between air pollution monitoring (2008-2011) and health examination (spirometry conducted between 1985-2010; supplementary table S2), sensitivity analyses replaced ESCAPE exposure estimates with estimates back extrapolated to the time of first and second spirometry (except for the time of first spirometry in ECRHS and EGEA, where no historical data was available, and of second spirometry in NSHD and SALIA conducted between 2006 and 2010, sufficiently close to the ESCAPE monitoring campaigns). During the past decades, air quality has in general improved. Given the lack of historic LUR models, ESCAPE could not individually estimate within-city contrasts of air quality for these past years. Instead, where available, annual means from fixed site monitoring stations were used to derive past annual mean concentrations for pollutants with available historic data $\left(\mathrm{NO}_{2}\right.$ and $\mathrm{PM} 10$ only). For each study participant's home address the back extrapolated concentration was obtained by multiplying the modelled ESCAPE annual mean concentration with the ratio between average annual concentrations as derived from the routine monitoring site(s) for the period in the past and for the ESCAPE measurement period time (details can be found in www.escapeproject.eu/manuals/) [12]. The procedures applied assumed that the within-city spatial contrasts remained proportional over time. Gulliver et al. [15] confirmed the validity of this assumption for the UK.

\section{Lung function metrics and outcomes}

FEV1 and FVC were used as outcome metrics. In cross-sectional analysis, we focused on lung function measured at the second spirometry (time point closest to ESCAPE air pollution monitoring). Change in lung function between first and second spirometry was assessed as both annual lung function change $\left(\mathrm{mL} \cdot \mathrm{year}^{-1}\right)$ and annual change in lung function as a percentage of the first spirometry value $\left(\% \cdot \mathrm{year}^{-1}\right.$ ) (supplementary material; methods: lung function metrics and outcomes section), with a negative value representing a decline. Data presented are restricted to absolute change as results did not materially differ for percent change as outcome.

\section{Statistical analyses}

First, study specific data were analysed separately following identical analytical procedures. Associations of air pollutants with lung function metrics were estimated using multivariable mixed linear regression models with a random intercept for ESCAPE areas with their own exposure monitoring and modelling. Three confounder models were specified $a$ priori, adjusting for an increasing number of covariates selected on the basis of previous cohort studies of air pollution and lung function and the availability of data for most cohorts, excluding missing values on any of the covariates. The covariate definitions were standardised across studies (supplementary material; methods section). In the absence of materially different effect estimates derived from models adjusting for additional covariates, we chose as main 
analytic model the one adjusting for age (years), age squared, height $(\mathrm{cm})$, sex, body mass index (BMI; $\mathrm{kg} \cdot \mathrm{m}^{-2}$ ), educational level (low as reference, medium, high), and smoking status (never as reference, ever). Models analysing traffic exposure indices were additionally adjusting for background $\mathrm{NO}_{2}$ concentrations. The traffic indicator coefficients are thus assumed to reflect the impact of pollutants highly concentrated along the roads. The median of traffic indicator values across all studies was chosen as cut-off for dichotomising the continuous traffic exposure $(\leqslant 5000$ and $>5000$ cars per day for traffic intensity on the nearest major road; $\leqslant 500$ and $>500$ car-km driven per day for the traffic intensity on major roads in a $100 \mathrm{~m}$ buffer) (supplementary material; methods: statistic models section). Traffic variables were also analysed on a continuous scale but this did not produce meaningful results.

Secondly, cohort-specific overall and stratum-specific effect estimates obtained by mixed linear regression models were meta-analysed (supplementary material; methods: meta-analysis section).

A pre-defined set of variables considering previous evidence and cohort differences was tested for effect modification. We compared the summary estimates of the two opposite subgroups (females versus males; not obese versus obese; never versus ever smokers; never asthma versus ever asthma) using a chi-square test with one degree of freedom. In sensitivity analyses we restricted the analytical model to non-movers and participants aged $\geqslant 30$ years (age at first spirometry).

A standardised analytical approach was used to minimise the possibility of differential bias across participating cohorts. We controlled for different known or potential individual confounding factors in our analyses. Moreover, we included random effects for the different cohort areas to adjust for geographic clustering of outcomes. Additionally, we performed several sensitivity analyses in selected subsamples to address specific potential biases (e.g. in the subsample of non-movers to address potential bias due to health-related changes in exposure).

Statistical analyses were performed using STATA, version 12 (Stata Statistical Software, Release 12; StataCorp., College Station, TX, USA).

\section{Results}

Study characteristics

Table 1 provides a description of the cohort specific study populations. The average age of the cohorts at the time of second spirometry ranged from 43 years (ECRHS) to 73 years (SALIA). The SALIA population, consisting exclusively of females, exhibited the lowest mean levels of FEV1 (2.20 L) and FVC $(2.91$ L) (table 1) (for the smaller PM subpopulation and for the cohort-specific lung function distributions stratified by sex, smoking and asthma status, refer to supplementary table S3).

\section{Air pollution exposure}

Table 2 shows the distribution of the air pollution metrics for each study area. Variance explained by LUR models varied between $55 \%$ and $92 \%$ for $\mathrm{NO}_{2}$ and between $68 \%$ and $90 \%$ for PM10 (supplementary table S4). Mean exposure was lowest for all air pollution metrics in NSHD. Within-study contrasts were smallest for SALIA and SAPALDIA, reflecting the restricted geographic region covered (supplementary table S5). The study specific correlations between the exposure metrics were generally highest between $\mathrm{NO}_{2}$ and $\mathrm{NO}_{\mathrm{x}}$ (rho of 0.90-0.98), but moderate to low between pollutants and traffic indicators (supplementary table S6). ESCAPE derived exposures were highly correlated with the exposures back-extrapolated to the time of the second spirometry $\left(\mathrm{rho}\left(\mathrm{NO}_{2}\right) \geqslant 0.94 ; \operatorname{rho}(\mathrm{PM} 10) \geqslant 0.91\right)$, but less strongly correlated with exposures back-extrapolated to the first spirometry $\left(0.56 \leqslant \operatorname{rho}\left(\mathrm{NO}_{2}\right) \leqslant 0.92 ; 0.47 \leqslant \operatorname{rho}(\mathrm{PM} 10) \leqslant 0.74\right)$.

\section{Association between air pollution and lung function}

The main meta-analysis results for associations of each air pollution metric with level and change of lung function are presented in table 3. No associations between any exposure metric and lung function decline were present, irrespective of covariate adjustment and subgroup (sex, obesity, asthma and smoking). Looking at levels of lung function cross-sectionally, we found higher $\mathrm{NO}_{2}$ and $\mathrm{NO}_{\mathrm{x}}$ exposures to be associated with lower levels of FVC and FEV1. An increase of $10 \mu \mathrm{g} \cdot \mathrm{m}^{-3}$ in $\mathrm{NO}_{2}$ exposure was associated with a $-14.0 \mathrm{~mL}$ lower level of FEV1 (95\% CI -25.8- -2.1) and $-14.9 \mathrm{~mL}$ lower level of FVC (95\% CI -28.7- -1.1) (table 3, figs 1 and 2). An increase of $20 \mu \mathrm{g} \cdot \mathrm{m}^{-3}$ in $\mathrm{NO}_{\mathrm{x}}$ exposure was associated with a lower level of FEV1, by $-12.9 \mathrm{~mL}(95 \% \mathrm{CI}-23.87-2.0)$ and of FVC, by $-13.3 \mathrm{~mL}(95 \% \mathrm{CI}-25.9$ $-0.7)$ and an increase of $10 \mu \mathrm{g} \cdot \mathrm{m}^{-3}$ in PM10 was associated with a lower level of FEV $1(-44.6 \mathrm{~mL}, 95 \% \mathrm{CI}$ -85.4- -3.8) and FVC (-59.0 $\mathrm{mL}, 95 \% \mathrm{CI}-112.3--5.7)$ (table 3). The other PM metrics were not associated with lung function level. Higher traffic load on major roads in a $100 \mathrm{~m}$ buffer from residential address was associated with lower levels of FEV1 (-32.34 mL, 95\% CI -59.30- -5.38). 
TABLE 1 Description of cohort-specific study populations

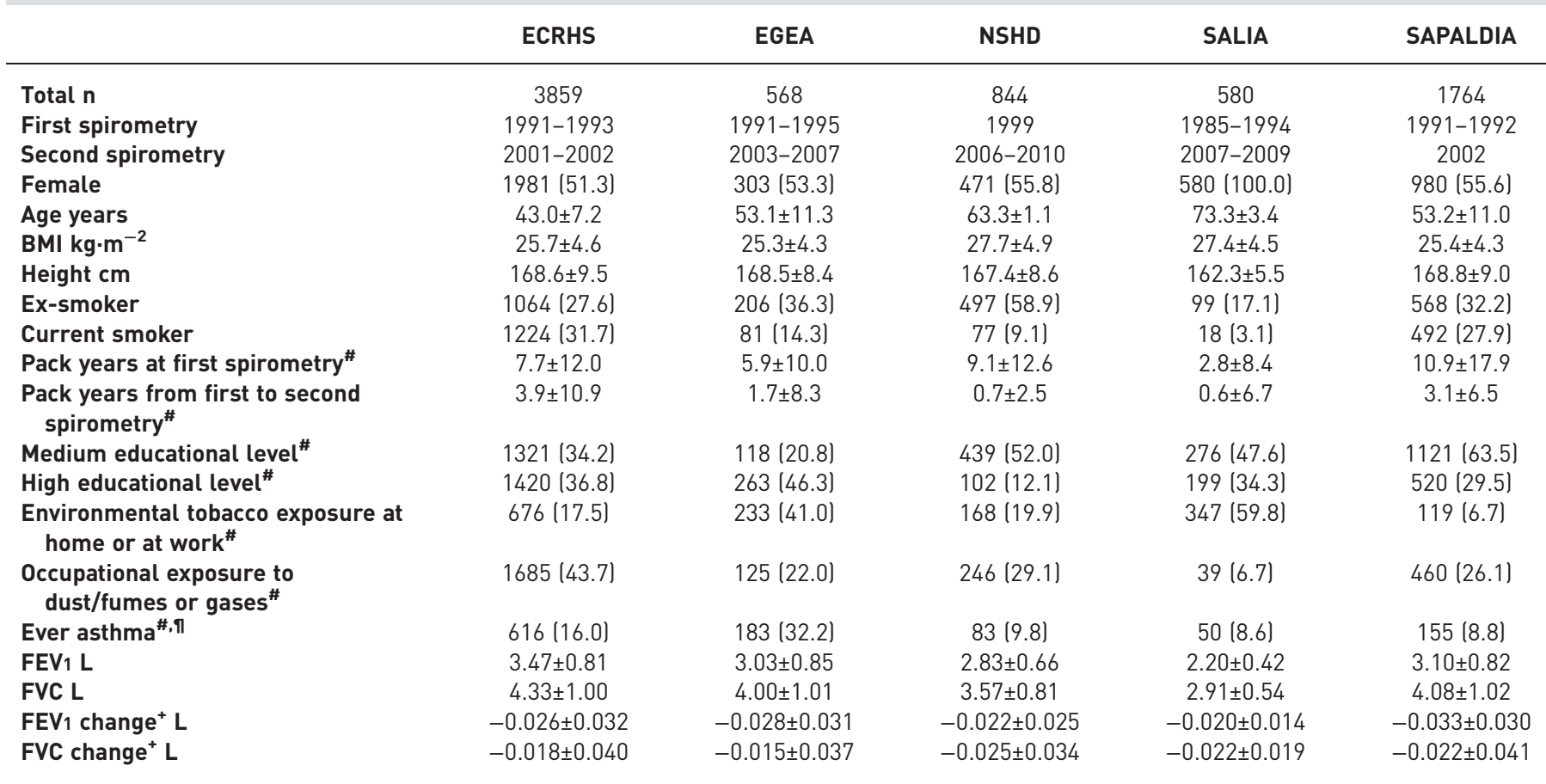

Data are presented as mean \pm SD for continuous variables, or $n(\%)$ for categorical variables, unless otherwise stated. Characteristics refer to time point of second spirometry, and are presented for the larger subgroup of participants included in the analysis of $\mathrm{NO}_{2}$ and $\mathrm{NO}_{x}$ and traffic indicators (characteristics for the smaller subgroup of participants included in the particulate matter metrics analyses are presented in supplementary table S1). BMI: body mass index; FEV1: forced expiratory volume in $1 \mathrm{~s}$; FVC: forced vital capacity. "\#: information missing on a limited number of subjects; ๆ": asthma diagnosed by a physician at first and/or at second spirometry; ${ }^{+}$: change in lung function between first and second spirometry.

TABLE 2 Distribution of all exposure estimates (annual averages of ambient air pollutants and traffic indicators), at participants residential addresses in each cohort

\begin{tabular}{|c|c|c|c|c|c|c|c|c|c|c|c|c|c|c|c|}
\hline Exposures & \multicolumn{3}{|c|}{ ECRHS } & \multicolumn{3}{|c|}{ EGEA } & \multicolumn{3}{|c|}{ NSHD } & \multicolumn{3}{|c|}{ SALIA } & \multicolumn{3}{|c|}{ SAPALDIA } \\
\hline $\mathrm{PM} 2.5 \mu \mathrm{g} \cdot \mathrm{m}^{-3}$ & 1830 & 15.9 & 7.0 & 342 & 15.3 & 2.0 & 751 & 9.5 & 1.5 & 580 & 17.8 & 1.7 & 729 & 16.8 & 1.1 \\
\hline $\mathrm{PM} 10 \mu \mathrm{g} \cdot \mathrm{m}^{-3}$ & 1830 & 25.8 & 9.7 & 342 & 25.1 & 4.0 & 751 & 15.7 & 1.9 & 580 & 26.7 & 2.1 & 729 & 23.2 & 2.3 \\
\hline Coarse $\mathrm{PM}^{\#} \mu \mathrm{g} \cdot \mathrm{m}^{-3}$ & 1830 & 10.3 & 4.7 & 342 & 9.4 & 3.3 & 751 & 6.4 & 0.8 & 580 & 9.4 & 1.6 & 729 & 6.5 & 1.9 \\
\hline $\mathrm{NO}_{2} \mu \mathrm{g} \cdot \mathrm{m}^{-3}$ & 3859 & 28.9 & 18.7 & 568 & 27.4 & 14.7 & 844 & 22.4 & 10.0 & 580 & 27.6 & 8.1 & 1764 & 27.0 & 7.7 \\
\hline $\begin{array}{l}\text { Traffic load on nearest major } \\
\text { road }^{+}\end{array}$ & 2687 & 1.45 & 1.67 & 568 & 1.37 & 1.58 & 844 & 0.27 & 0 & 580 & 0.72 & 0.32 & 1671 & 0.94 & 1.42 \\
\hline $\begin{array}{l}\mathrm{NO}_{2} \text { back-extrapolated to first } \\
\text { spirometry } \mu \mathrm{g} \cdot \mathrm{m}^{-3}\end{array}$ & $N A^{\S}$ & $N A^{\S}$ & $N A^{\S}$ & $N A^{\S}$ & $N A^{\S}$ & $N A^{\S}$ & 841 & 26.3 & 11.2 & 580 & 36.0 & 14.0 & 1762 & 47.7 & 12.3 \\
\hline $\begin{array}{l}\text { PM10 back-extrapolated to first } \\
\text { spirometry } \mu \mathrm{g} \cdot \mathrm{m}^{-3}\end{array}$ & $N A^{\S}$ & $N A^{\S}$ & $N A^{\S}$ & $N A^{\S}$ & $N A^{\S}$ & $N A^{\S}$ & 748 & 22.0 & 2.6 & 580 & 47.7 & 13.6 & 726 & 46.2 & 4.0 \\
\hline
\end{tabular}

IQR: interquartile range; PM2.5: particulate matter with a diameter of $\leqslant 2.5 \mu \mathrm{m}$; PM10: particulate matter with a diameter of $\leqslant 10 \mu \mathrm{m} .{ }^{\#}$ : fraction of PM2.5 to relative to PM10; ": cars per day; ${ }^{+}$: traffic load on nearest major road within a $100 \mathrm{~m}$ buffer presented in thousands of car-km driven per day; ${ }^{\S}$ : no complete exposure back-extrapolation to first spirometry available; ${ }^{f}$ : no back-extrapolation applied as time point of second spirometry coincides with time point of ESCAPE monitoring campaign. 
Associations observed for $\mathrm{NO}_{2}$ and $\mathrm{PM} 10$ with $\mathrm{FEV} 1$ and $\mathrm{FVC}$ at second spirometry remained largely unaltered when ESCAPE exposure estimates of $\mathrm{NO}_{2}$ and PM10 in ECRHS, EGEA and SAPALDIA were replaced with $\mathrm{NO}_{2}$ and PM10 estimates back-extrapolated to the time point of the second spirometry. The inverse association between PM10 and FVC became stronger and statistically significant (supplementary table S7).

In subgroup analysis, the $\mathrm{NO}_{2}$ and $\mathrm{NO}_{\mathrm{x}}$ (data not shown) associations with FEV1 and FVC were particularly observed in obese participants (FEV1: figures 3 and 4; FVC: supplementary figures S2 and S3) ( $\mathrm{p}$-values for heterogeneity, obese versus non-obese: $\mathrm{p}=0.098$ for $\mathrm{NO}_{2} / \mathrm{FEV}_{1}$ (figures 3 and 4); $\mathrm{p}=0.026$ for $\mathrm{NO}_{2} / \mathrm{FVC}$ (supplementary figures $\mathrm{S} 2$ and $\mathrm{S} 3$ ); $\mathrm{p}=0.050$ for $\mathrm{NO}_{\mathrm{x}} / \mathrm{FVC}$ ). All other tested factors (sex, smoking and asthma status) showed no or only weak evidence for modification of the air pollution lung function associations $\left(\mathrm{NO}_{2}\right.$ : supplementary table S8). The effect modification by obesity was also evident in sex-stratified analyses, with substantially stronger inverse $\mathrm{NO}_{2}$ and $\mathrm{NO}_{\mathrm{x}}$ associations with FEV1 and $\mathrm{FVC}$, in both obese females and males ( $\mathrm{NO}_{2}$ : supplementary table $\left.\mathrm{S} 9\right)$.

In sensitivity analysis, looking at non-movers and participants aged 30 years or more, we did not find a particular difference from the observed main associations (supplementary table S10).

\section{Discussion}

This study in adults contributes to the evidence of long-term exposure to ambient air pollution being associated with the level of lung function. The meta-analysis was based on individual-level exposure assessment standardised across different cities and regions in Europe. Impaired lung function characterised by reduced FEV1, a powerful marker of future morbidity and mortality [16], exhibited the most consistent association with different pollution metrics. It was inversely related to nitrogen oxides and PM10, as well as to traffic load at the residential address. Our data suggest that obese persons are particularly sensitive to air pollution.

\section{Comparison with other studies}

Results from previous cross-sectional studies predominantly relied on exposure measured at the level of a few communities. They point to an inverse association of adult lung function with air pollution and traffic load $[1,6]$, but as the measurement and meaning of specific pollution metrics differs between studies their comparative relevance remains inconclusive. This also applies to the current study. According to the site-specific differences in correlations between exposure metrics (supplementary table S6) they capture different sources of air pollution and thereby different components. The absence of associations with most of the PM metrics may additionally be rooted in the more limited sample size. PM measurements were only performed in a limited number of centres. $\mathrm{NO}_{2}$, which characterises the spatial variation of traffic related air pollution, has been linked with stronger lung function impairment depending on the parameter studied, but evidence that PM effects are stronger has also been published $[3,7]$.

The interaction between air pollution exposure and obesity on lung function parallels a recent SAPALDIA report and adds evidence to the interdependence of the two important global epidemics of environmental pollution and obesity [17]. Many studies have demonstrated an association between obesity and lung function. Lung function improves after weight loss in obese persons, and weight gain is associated with lung function decline in asthmatics and in the general population [17-19]. The mechanical effect of excess body fat on lung volumes and airway calibre is well accepted [18]. In addition, inflammatory pathways may play a role, as overweight is associated with an underlying state of oxidative stress and inflammation [17, 20]. Air pollution and obesity seemingly have more than additive effects on systemic inflammation [21, 22]. In animal models, ozone-induced pulmonary injury and inflammation were greater in obese versus lean mice [23, 24]. In humans, acute ozone effects on lung function were more prominent among obese subjects $[25,26]$.

The null finding investigating the association of air pollution with the change in lung function is consistent with a previous report from the ECRHS cohort [27], but extends the finding to older cohorts. In light of the positive findings for the cross-sectional associations, this null finding may be surprising. Cross-sectional differences are expected to result at least in part from differences in age-related decline. Based on the current results it seems premature to conclude that long-term exposure to air pollution does not affect FEV1 and FVC decline.

\section{Strengths and weaknesses}

Our study benefits from a large number of observations, and the multicentre design across different European regions, covering a broad range of different types of environment and climates and a wide age range of participants. Furthermore, the individual-level exposure assessment was harmonised, a common study protocol of exposure and outcome definition was developed and the analytic approach was standardised. However, this study has also several limitations. 
TABLE 3 Results of meta-analyses for the association between level and change of lung function and exposure to air pollution and traffic intensity indicators

Exposure (increment)

Level of lung function $(\mathrm{mL})^{\#}$

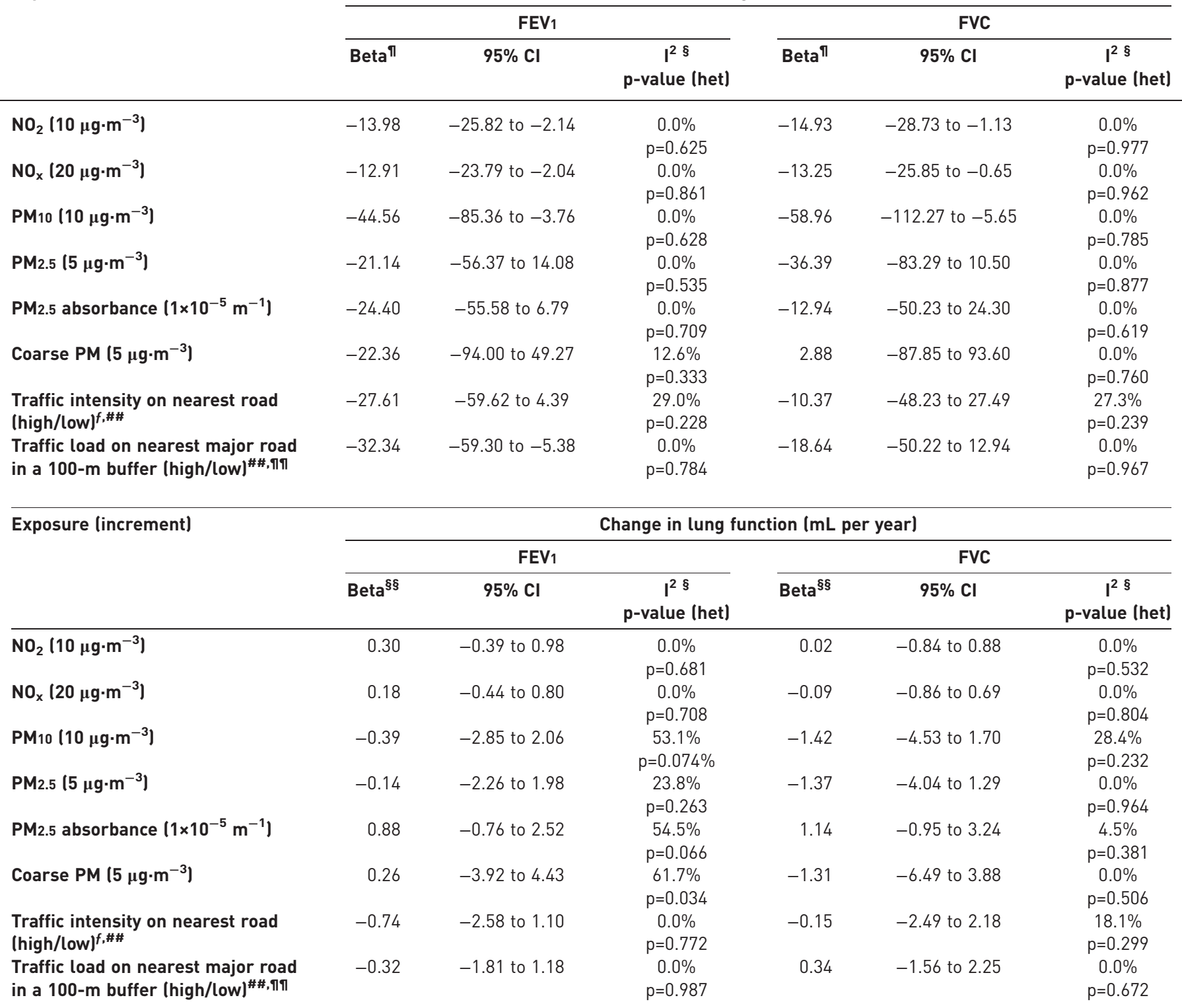

Exposure (increment)

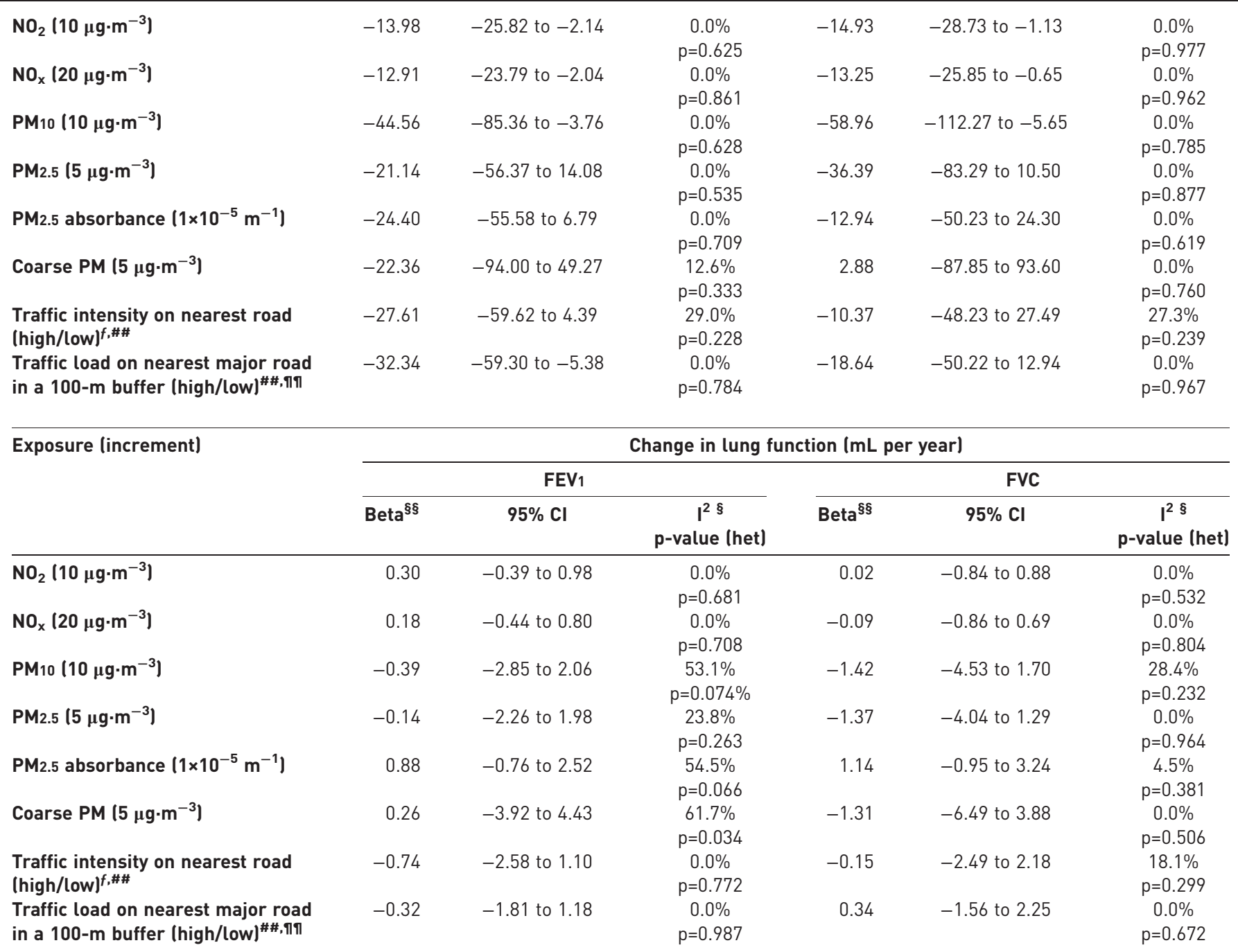

FEV1: forced expiratory volume in $1 \mathrm{~s}$; FVC: forced vital capacity; PM: particulate matter. ${ }^{\text {: }}$ level of lung function for cross-sectional analysis was derived from second spirometry. ": the beta values for the association between level of lung function and exposure are adjusted for age, age squared, height, sex, body mass index (BMI), highest educational level, and smoking status at second spirometry; a negative sign indicates lower lung function with increasing exposure. ${ }^{\S}: 1^{2}$ and Cochran's test for heterogeneity of effect estimates between cohorts. ${ }^{f}:$ low traffic intensity on nearest road: $\leqslant 5000$ cars per day; high: $>5000$ cars per day. \#\#: associations with traffic intensity (high/low) and traffic load (high/ low) were additionally adjusted for background $\mathrm{NO}_{2}$ concentrations. П11: low traffic load on the nearest major road in a $100-\mathrm{m}$ buffer: $\leqslant 500$ car-km driven per day; high: $>500$ car-km driven per day. $\S^{\S}$ : the beta values of the association between change in lung function and exposure are adjusted for sex, age and height at first spirometry, highest educational level, smoking at first spirometry, smoking cessation and change in $\mathrm{BMI}$ to the second spirometry; a negative sign indicates steeper lung function decline with increasing exposure.

Several methodological issues related to outcome and exposure assessment may have biased the longitudinal association. Data from only two spirometry time points and from spirometries conducted in different seasons and times of the day may have decreased the precision in estimating lung function decline. As common in long-term lung function studies, spirometry devices had to be updated with new software or replaced during follow-up. Such changes can be an inherent source of differences in the measured lung function and its temporal change [28]. The inherent limitations in exposure assessment are 


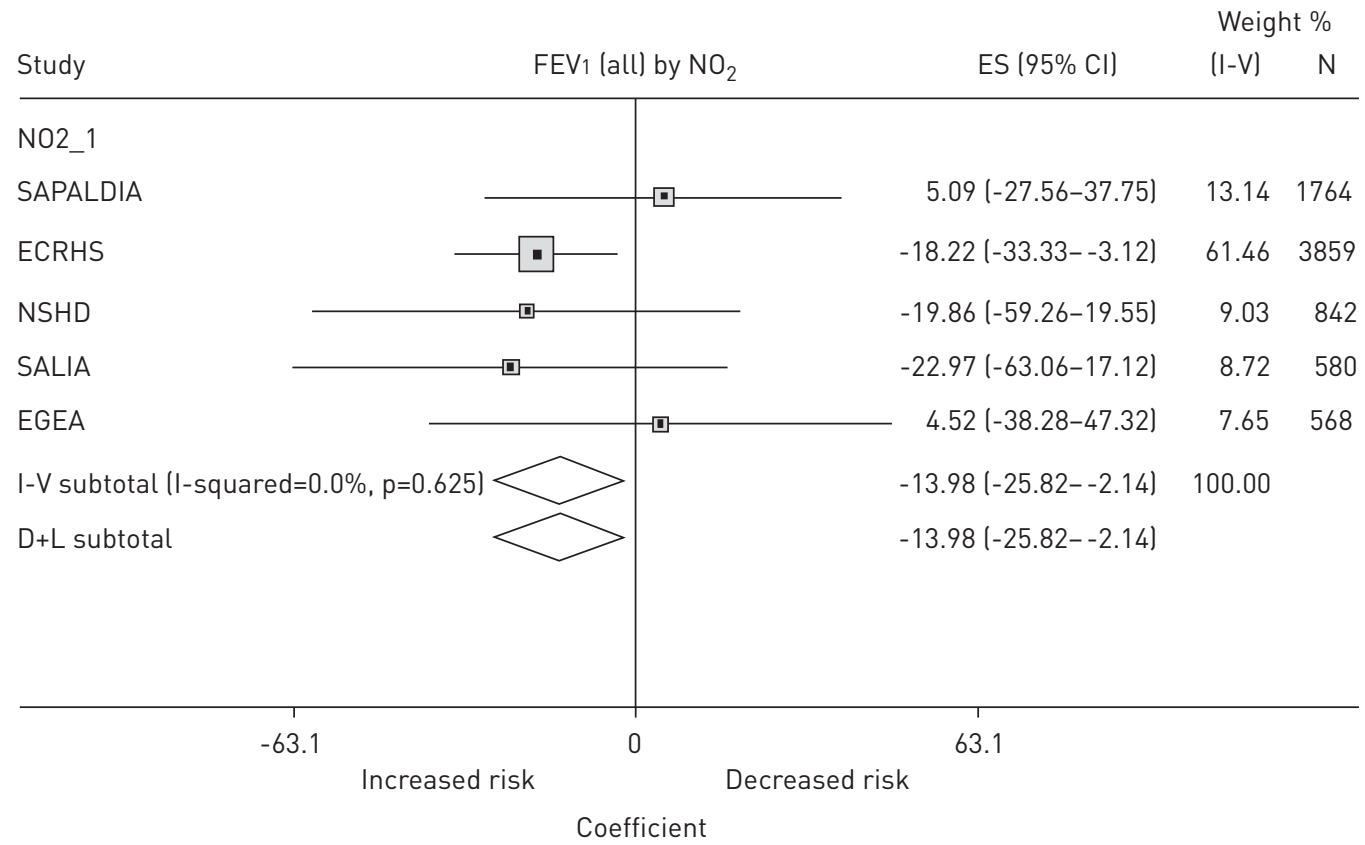

FIGURE 1 Forest plot displaying the study-specific mixed linear regression model estimates of the association of $\mathrm{NO}_{2}$ with level of forced expiratory volume in $1 \mathrm{~s}$ (FEV 1 ; in $\mathrm{mL}$ ) (based on all study participants living in sites with ESCAPE models available). NO2_1 indicates $\mathrm{NO}_{2}$ measured at time of ESCAPE. Associations with lung function measures are presented as increments in $\mathrm{NO}_{2}$ per $10 \mu \mathrm{g} \cdot \mathrm{m}^{-3}$. I-square: variation in estimated effects attributable to heterogeneity. D $+\mathrm{L}$ (Der Simonian and Laird method): pooled estimate of all studies. The mixed linear regression models were adjusted for: age, age squared, height, sex, body mass index, highest educational level, and smoking status at second spirometry; negative estimates indicated lower lung function with increasing exposure. ES: effect size.

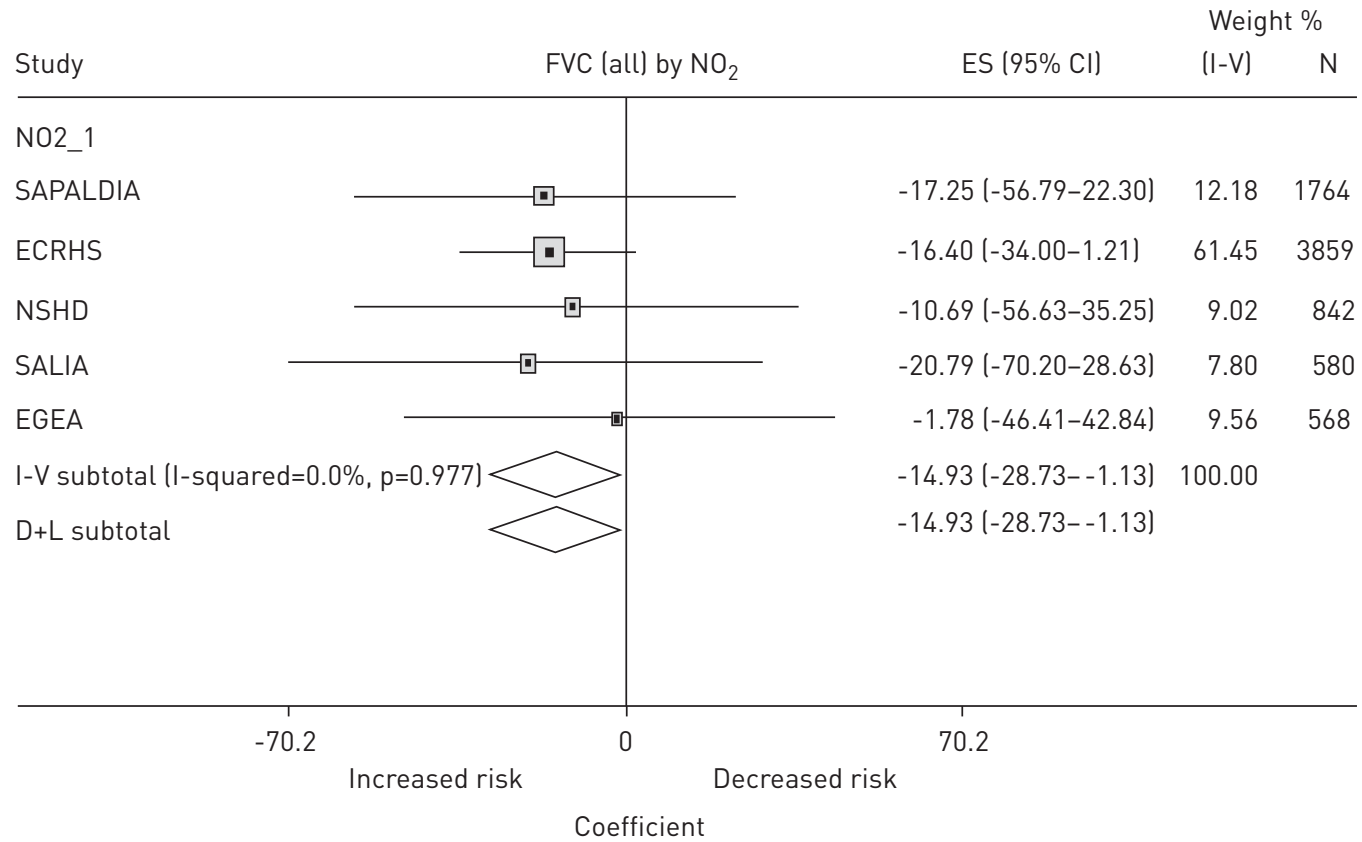

FIGURE 2 Forest plot displaying the study-specific mixed linear regression model estimates of the association of $\mathrm{NO}_{2}$ with level of forced vital capacity FVC; in $\mathrm{mL}$ ) (based on all study participants living in sites with ESCAPE models available). $\mathrm{NO}_{2} \_1$ indicates $\mathrm{NO}_{2}$ measured at time of ESCAPE. Associations with lung function measures are presented as increments in $\mathrm{NO}_{2}$ per $10 \mu \mathrm{g} \cdot \mathrm{m}^{-3}$. I-square: variation in estimated effects attributable to heterogeneity. D+L (Der Simonian and Laird method): pooled estimate of all studies. The mixed linear regression models were adjusted for: age, age squared, height, sex, body mass index, highest educational level, and smoking status at second spirometry; negative estimates indicated lower lung function with increasing exposure. ES: effect size. 
Weight \%

Study

FEV1 (not obese) by $\mathrm{NO}_{2}$

$\mathrm{ES}(95 \% \mathrm{Cl})$

$(I-V) \quad N$

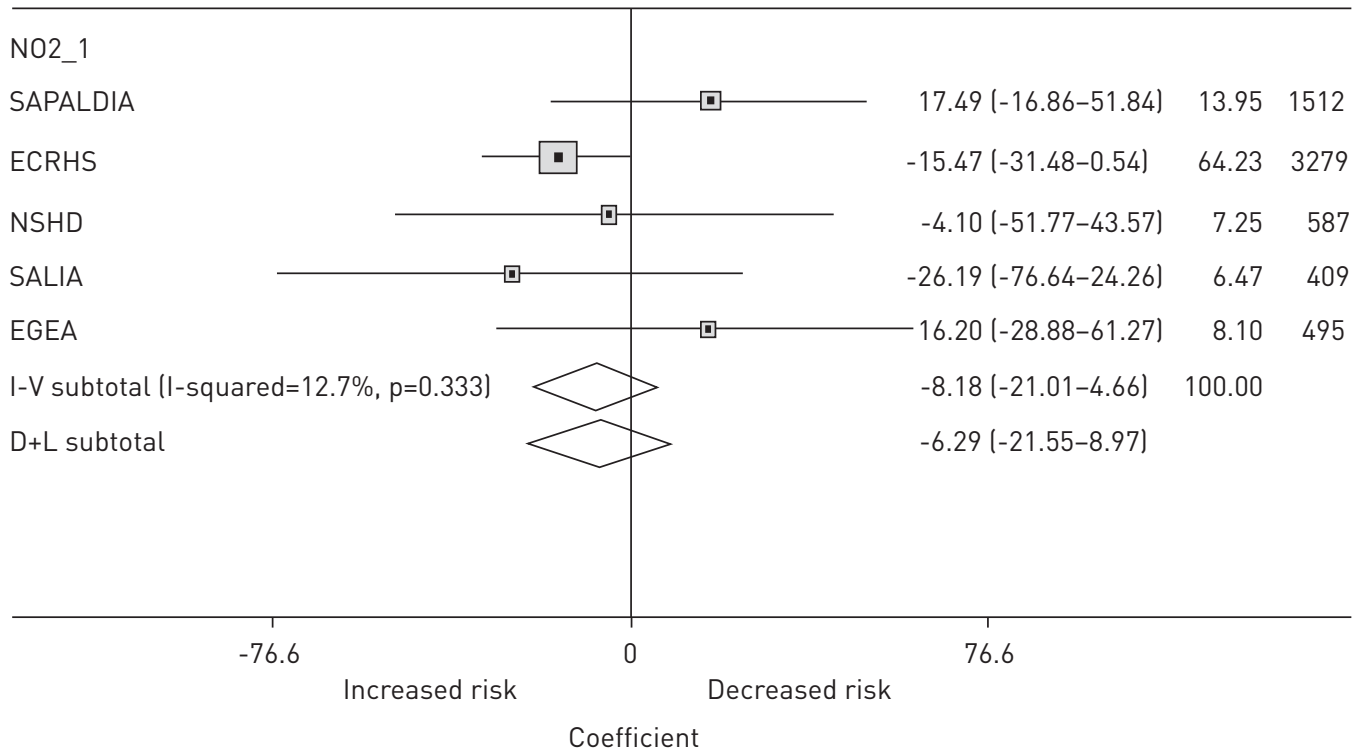

FIGURE 3 Forest plot displaying the study-specific mixed linear regression model estimates of the association of $\mathrm{NO}_{2}$ with level of forced expiratory volume in $1 \mathrm{~s}\left(\mathrm{FEV}_{1}\right.$; in $\mathrm{mL}$ ) in participants stratified as not obese (body mass index $(\mathrm{BMI})<30 \mathrm{~kg} \cdot \mathrm{m}^{-2}$ ). NO2_1 indicates $\mathrm{NO}_{2}$ measured at time of ESCAPE. Associations with lung function measures are presented as increments in $\mathrm{NO}_{2}$ per $10 \mu \mathrm{g} \cdot \mathrm{m}^{-3}$. I-square: variation in estimated effects attributable to heterogeneity. D+L (Der Simonian and Laird method): pooled estimate of all studies. The mixed linear regression models were adjusted for: age, age squared, height, sex, BMI, highest educational level, and smoking status at second spirometry; negative estimates indicated lower lung function with increasing exposure. p-value for heterogeneity, obese versus non-obese: 0.098 for FEV1. ES: effect size.

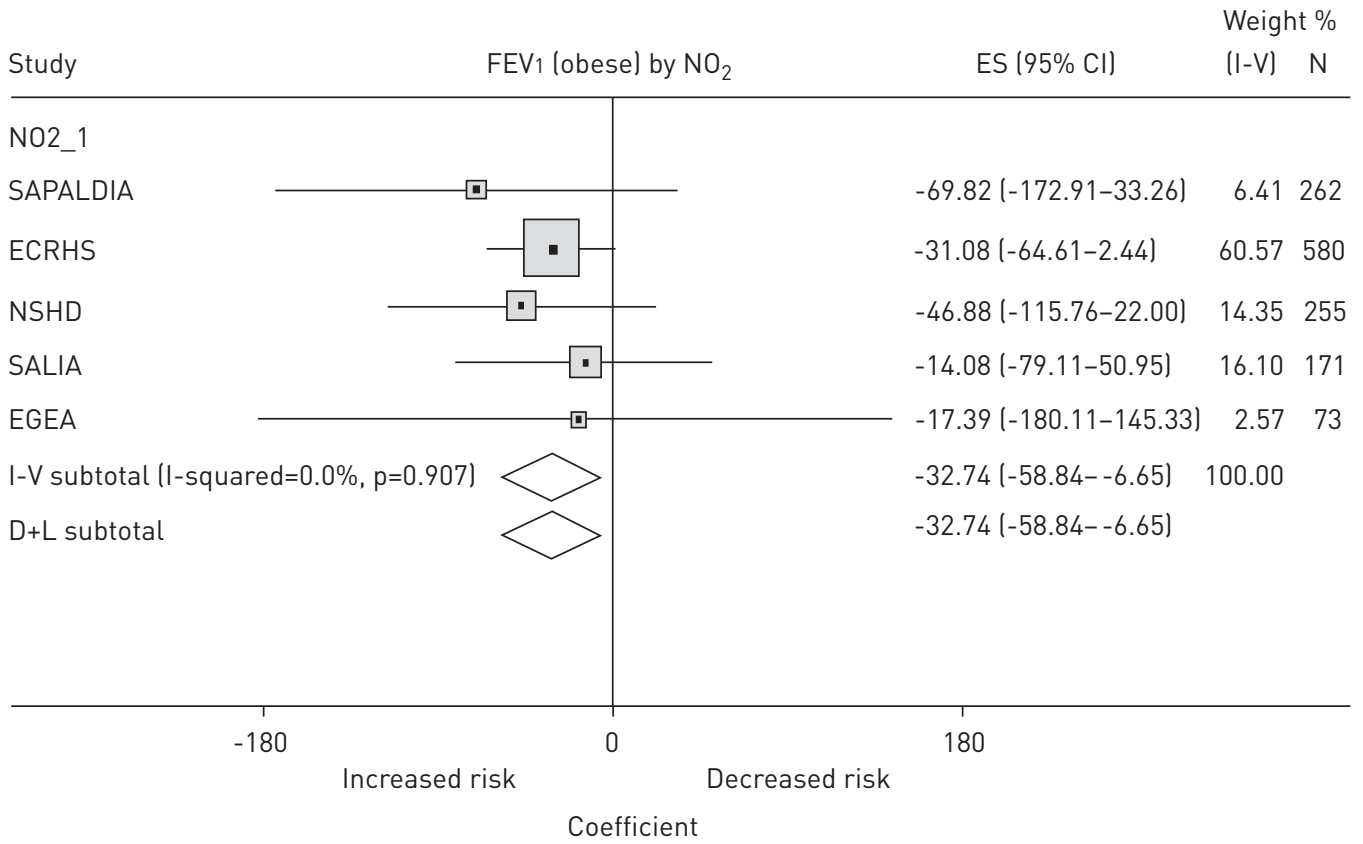

FIGURE 4 Forest plot displaying the study-specific mixed linear regression model estimates of the association of $\mathrm{NO}_{2}$ with level of forced expiratory volume in $1 \mathrm{~s}\left(\mathrm{FEV}\right.$; in $\mathrm{mL}$ ) in obese participants (body mass index (BMI) $\geqslant 30 \mathrm{~kg} \cdot \mathrm{m}^{-2}$ ). $\mathrm{NO}_{2} 1$ indicates $\mathrm{NO}_{2}$ measured at time of ESCAPE. Associations with lung function measures are presented as increments in $\mathrm{NO}_{2}$ per $10 \mu \mathrm{g} \cdot \mathrm{m}^{-3}$. I-square: variation in estimated effects attributable to heterogeneity. D+L (Der Simonian and Laird method): pooled estimate of all studies. The mixed linear regression models were adjusted for: age, age squared, height, sex, BMI, highest educational level, and smoking status at second spirometry; negative estimates indicated lower lung function with increasing exposure. p-value for heterogeneity, obese versus non-obese: 0.098 for FEV1. ES: effect size. 
also amplified in the longitudinal analyses. Most importantly, back-extrapolation of residential pollution levels is of prime relevance to properly characterise exposure at first spirometry, and then derive the change in exposure over time. Uncertainties with the back-extrapolated values may be substantial and if unrelated to the true exposure, may bias findings towards the null. In addition LUR models have inherent limitations. Cross-validation of the LURs varied across regions [10,11] and performance of models based on 20 or 40 measurement sites may be overestimated [29, 30].

Additional limitations of the study beyond back-extrapolation include the non-availability of information on short-term exposure at the time of spirometry for a sufficient number of sites and pollution metrics. Adjustment for short-term exposure in SAPALDIA did not alter the associations. Heterogeneity of study populations poses a challenge to meta-analysis and makes it difficult to exclude residual confounding and unrecognised effect modification. The associations were not sensitive to the SALIA study consisting exclusively of females and exhibiting the lowest mean levels of lung function (supplementary figures S4 and 55 for associations of $\mathrm{NO}_{2}$ with FEV1 and FVC in females). Non-participation at follow-up of subjects with low lung function may bias observed associations or limit their generalisability. In SAPALDIA, subjects with better lung function were more likely to participate in the second spirometry, but sensitivity analyses using inverse probability weighting to account for non-participation did not alter associations between air pollution and lung function [8].

\section{Conclusion}

The current study, which includes a large number of observations from different regions, environments and climates in Europe, and standardized exposure assessment, provides firm support to an adverse association between ambient air pollution and lung function in adults. Inverse associations could be observed at very low air pollution levels in Europe. The policy relevance of these findings is further strengthened by the observation that obese persons may be particularly susceptible.

\section{Acknowledgements}

We acknowledge the support of an external advisory board consisting of Mike Jerrett (UC Berkeley, Berkeley, CA, USA), Joel Kaufman (University of Washington, Seattle, WA, USA), Ross Anderson (King's College London, London, UK), Michal Krzyzanowski (World Health Organization, Bonn, Germany), Aaron Cohen (Health Effects Institute, Boston, MA, USA).

We thank all study members and staff involved in data collections in each cohort and also the respective funding bodies for ECRHS, EGEA, NSHD, SALIA and SAPALDIA.

ECRHS

The ECRHS data incorporated in this analysis would not have been available without the collaboration of the following individuals and their research teams.

ECRHS co-ordinating centre: P. Burney, D. Jarvis, S. Chinn, J. Knox (ECRHS II), C. Luczynska ${ }^{\dagger}$, J. Potts.

Steering Committee for ECRHS II: P. Burney, D. Jarvis, S. Chinn, J.M. Anto, I. Cerveri, R. deMarco, T. Gislason, J. Heinrich, C. Janson, N. Kunzli, B. Leynaert, F. Neukirch, T. Rochat, J. Schouten, J. Sunyer, C. Svanes, P. Vermeire ${ }^{\dagger}$, M. Wjst.

Principal Investigators and Senior Scientific Teams for ECRHS II: Australia: Melbourne (M. Abramson, R. Woods, E.H. Walters, F. Thien); Belgium: South Antwerp and Antwerp City (P. Vermeire ${ }^{\dagger}$, J. Weyler, M. Van Sprundel, V. Nelen); Denmark: Aarhus (E.J. Jensen); Estonia: Tartu (R. Jogi, A. Soon); France: Paris (F. Neukirch, B. Leynaert,

R. Liard, M. Zureik), Grenoble (I. Pin, J. Ferran-Quentin), Bordeaux (A. Taytard, C. Raherison), Montpellier (J. Bousquet, P. Demoly); Germany: Erfurt (J. Heinrich, M. Wjst, C. Frye, I. Meyer), Hamburg (K. Richter); Iceland: Reykjavik (T. Gislason, E. Bjornsson, D. Gislason, T. Blondal, A. Karlsdottir); Italy: Turin (M. Bugiani, P. Piccioni, E. Caria, A. Carosso, E. Migliore, G. Castiglioni), Verona (R. de Marco, G. Verlato, E. Zanolin, S. Accordini, A. Poli, V. Lo Cascio, M. Ferrari), Pavia (A. Marinoni, S. Villani, M. Ponzio, F. Frigerio, M. Comelli, M. Grassi, I. Cerveri, A. Corsico); the Netherlands: Groningen and Geleen (J. Schouten, M. Kerkhof); Norway: Bergen (A. Gulsvik, E. Omenaas, C. Svanes, B. Laerum); Spain: Barcelona (J.M. Anto, J. Sunyer, M. Kogevinas, J.P. Zock, X. Basagana, A. Jaen, .F Burgos), Huelva (J. Maldonado, A. Pereira, J.L. Sanchez), Albacete (J. Martinez-Moratalla Rovira, E. Almar), Galdakao (N. Muniozguren, I. Urritia), Oviedo (F. Payo); Sweden: Uppsala (C. Janson, G. Boman, D. Norback, M. Gunnbjornsdottir), Goteborg (K. Toren, L. Lillienberg, A.C. Olin, B. Balder, A. Pfeifer-Nilsson, R. Sundberg), Umea (E. Norrman, M. Soderberg, K. Franklin, B. Lundback, B. Forsberg, L. Nystrom); Switzerland: Basel (N. Kunzli, B. Dibbert, M. Hazenkamp, M. Brutsche, U. Ackermann-Liebrich); UK: Norwich (D. Jarvis, B. Harrison), Ipswich (D. Jarvis, R. Hall, D. Seaton); USA: Portland (M. Osborne, S. Buist, W. Vollmer, L. Johnson).

The excellent fieldwork by Gabriele Wölke and Matthias Birk is highly acknowledged.

EGEA

Coordination: V. Siroux (epidemiology, PI since 2013), F. Demenais (genetics), I. Pin (clinical aspects), R. Nadif (biology), F. Kauffmann (PI 1992-2012). 
Respiratory epidemiology: Inserm U 700, Paris: M. Korobaeff (Egea1), F. Neukirch (Egea1); Inserm U 707, Paris: I. Annesi-Maesano (Egea1-2); Inserm CESP/U 1018, Villejuif: F. Kauffmann, N. Le Moual, R. Nadif, M.P. Oryszczyn (Egea1-2), R. Varraso; Inserm U 823, Grenoble: V. Siroux.

Genetics: Inserm U 393, Paris: J. Feingold; Inserm U 946, Paris: E. Bouzigon, F. Demenais, M.H. Dizier; CNG, Evry: I. Gut (now CNAG, Barcelona, Spain), M. Lathrop (now Univ. McGill, Montreal, Canada).

Clinical centres: Grenoble: I. Pin, C. Pison; Lyon: D. Ecochard (Egea1), F. Gormand, Y. Pacheco; Marseille: D. Charpin (Egea1), D. Vervloet (Egea1-2); Montpellier: J. Bousquet; Paris Cochin: A. Lockhart (Egea1), R. Matran (now in Lille); Paris Necker: E. Paty (Egea1-2), P. Scheinmann (Egea1-2); Paris-Trousseau: A. Grimfeld (Egea1-2), J. Just.

Data and quality management: Inserm ex-U155 (Egea1): J. Hochez; Inserm CESP/U 1018, Villejuif: N. Le Moual; Inserm ex-U780: C. Ravault (Egea1-2); Inserm ex-U794: N. Chateigner (Egea1-2); Grenoble: J. Quentin-Ferran (Egea1-2).

NHSD

We acknowledge the NSHD participants and the NSHD scientific and data collection teams.

SALIA

Over the past decades, many scientists, study nurses and laboratories were involved in conducting the study. As representatives for all these people we would like to thank especially Reinhard Dolgner (MD) for organising the baseline study and Barbara Schulten as study nurse for her help in organising the follow-up study. We are most grateful for all the females from the Ruhr area and from Borken who participated in the study over the decades.

\section{SAPALDIA}

Study directorate: T. Rochat (pneumology), N.M. Probst Hensch (epidemiology/genetic and molecular biology), J.M. Gaspoz (cardiology), N. Künzli (epidemiology/exposure), C. Schindler (statistics).

Scientific team: J.C. Barthélémy (cardiology), W. Berger (genetic and molecular biology), R. Bettschart (pneumology), A. Bircher (allergology), G. Bolognini (pneumology), O. Brändli (pneumology), C. Brombach (nutrition), M. Brutsche (pneumology), L. Burdet (pneumology), M. Frey (pneumology), U. Frey (paediatrics), M.W. Gerbase (pneumology), D. Gold (epidemiology / cardiology / pneumology), E. de Groot (cardiology), W. Karrer (pneumology), R. Keller (pneumology), B. Knöpfli (pneumology), B. Martin (physical activity), D. Miedinger (occupational health), U. Neu (exposure), L. Nicod (pneumology), M. Pons (pneumology), F. Roche (cardiology), T. Rothe (pneumology), E. Russi (pneumology), P. Schmid-Grendelmeyer (allergology), A. Schmidt-Trucksäss (physical activity), A. Turk (pneumology), J. Schwartz (epidemiology), D. Stolz (pneumology), P. Straehl (exposure), J.M. Tschopp (pneumology), A. von Eckardstein (clinical chemistry), E. Zemp Stutz (epidemiology).

Scientific team at coordinating centres: M. Adam (epidemiology/genetic and molecular biology), E. Boes (genetic and molecular biology), P.O. Bridevaux (pneumology), D. Carballo (cardiology), E. Corradi (epidemiology), I. Curjuric (epidemiology), J. Dratva (epidemiology), A. Di Pasquale (statistics), L. Grize (statistics), D. Keidel (statistics), S. Kriemler (physical activity), A. Kumar (genetic and molecular biology), M. Imboden (genetic and molecular biology), N. Maire (statistics), A. Mehta (epidemiology), F. Meier (epidemiology), H. Phuleria (exposure), E. Schaffner (statistics), G.A. Thun (genetic and molecular biology), A. Ineichen (exposure), M. Ragettli (epidemiology), M. Ritter (exposure), T. Schikowski (epidemiology), G. Stern (paediatrics), M. Tarantino (statistics), M. Tsai (epidemiology), M. Wanner (physical activity).

The study could not have been done without the help of the study participants, technical and administrative support and the medical teams and field workers at the local study sites.

Local fieldworkers: Aarau: S. Brun, G. Giger, M. Sperisen, M. Stahel; Basel: C. Bürli, C. Dahler, N. Oertli, I. Harreh, F. Karrer, G. Novicic, N. Wyttenbacher; Davos: A. Saner, P. Senn, R. Winzeler; Geneva: F. Bonfils, B. Blicharz, C. Landolt, J. Rochat; Lugano: S. Boccia, E. Gehrig, M.T. Mandia, G. Solari, B. Viscardi; Montana: A.P. Bieri, C. Darioly, M. Maire; Payerne: F. Ding, P. Danieli A. Vonnez; Wald: D. Bodmer, E. Hochstrasser, R. Kunz, C. Meier, J. Rakic, U. Schafroth, A. Walder.

Administrative staff: C. Gabriel, R. Gutknecht.

The authors wish to acknowledge the funding provided to the individual study cohorts as follows.

ECRHS was supported by the European Commission, as part of their Quality of Life program. The coordination of ECRHS II was supported by the European Commission, as part of their Quality of Life programme. The following bodies funded the local studies in ECRHS II in this article: Albacete-Fondo de Investigaciones Santarias (grant code: $97 /$ 0035-01, 13 99/0034-01, and 99/0034-02) (Hospital Universitario de Albacete, Consejeria de Sanidad); Antwerp-FWO (Fund for Scientific Research), Flanders, Belgium (grant code: G.0402.00) (University of Antwerp, Flemish Health Ministry); Barcelona-Fondo de Investigaciones Sanitarias (grant code: 99/0034-01, and 99/0034-02), Red Respira (RTIC 03/11 ISC IIF); Ciber of Epidemiology and Public Health was established and founded by Instituto de Salud Carlos III; Erfurt-GSF-National Research Centre for Environment and Health, Deutsche Forschungsgemeinschaft (DFG) (grant code FR 1526/1-1); Galdakao-Basque Health Department; Grenoble-Programme Hospitalier de Recherche Clinique-DRC de Grenoble 2000 no.2610, Ministry of Health, Direction de la Recherche Clinique, Ministere de l'Emploi et de la Solidarite, Direction Generale de la Sante, CHU de Grenoble, Comite des Maladies Respiratoires de l'Isere; Ipswich and Norwich-National Asthma Campaign (UK); Huelva-Fondo de Investigaciones Sanitarias (FIS) (grant code: 97/0035-01, 99/0034-01, and 99/0034-02); Oviedo-Fondo de Investigaciones Santarias (FIS) (grant code: 97/0035-01, 99/ 0034-01, and 99/0034-02); Paris-Ministere de l'Emploi et de la Solidarite, Direction Generale de la Sante, UCBPharma (France), Aventis (France), Glaxo France, Programme Hospitalier de Recherche Clinique-DRC de Grenoble 2000 no. 2610, Ministry of Health, Direction de la Recherche Clinique, CHU de Grenoble; measurements and models for PM in 
Grenoble (ECRHS) were funded by Region Rhônes-Alpes; Pavia-Glaxo, Smith and Kline Italy, Italian Ministry of University and Scientific and Technological Research (MURST), Local University Funding for Research 1998 and 1999 (Pavia, Italy); Turin-ASL 4 Regione Piemonte (Italy), AO CTO/ICORMA Regione Piemonte (Italy), Ministero dell'Università e della Ricerca Scientifica (Italy), Glaxo Wellcome spa (Verona, Italy); Umeå-Swedish Heart Lung Foundation, Swedish Foundation for Health Care Sciences and Allergy Research, Swedish Asthma and Allergy Foundation, Swedish Cancer and Allergy Foundation; Verona-University of Verona; Italian Ministry of University and Scientific and Technological Research (MURST); Glaxo, Smith and Kline Italy.

EGEA is funded in part by PHRC-Paris, PHRC-Grenoble, ANR 05-SEST-020-02/05-9-97, ANR-06-CEBS, ANRCES-2009, Région Nord Pas-de-Calais, Merck Sharp and Dohme (MSD).

NSHD and Profs R. Hardy and D. Kuh are supported by core funding and grant funding (U1200632239 and U12309272) from the UK Medical Research Council. The authors acknowledge the NSHD participants and the NSHD scientific and data collection teams.

SALIA received funds from the German state (NRW) and federal Ministries of the Environment. The follow-up investigation was funded by the DGUV (German statutory accident assurance) VT 266.1.

SAPALDIA received funds from the Swiss National Science Foundation (grants no 33CSCO-134276/1, 33CSCO-108796, 3247BO-104283, 3247BO-104288, 3247BO-104284, 3247-065896, 3100-059302, 3200-052720, 3200-042532, 4026-028099), the Federal Office for Forest, Environment and Landscape and several Federal and Cantonal authorities.

\section{References}

1 Sunyer J. Lung function effects of chronic exposure to air pollution. Thorax 2009; 64: 645-646.

2 Anderson JO, Thundiyil JG, Stolbach A. Clearing the air: a review of the effects of particulate matter air pollution on human health. J Med Toxicol 2012; 8: 166-175.

3 Gehring U, Gruzieva O, Agius RM, et al. Air pollution exposure and lung function in children: The ESCAPE Project. Environ Health Perspect 2013; 121: 1357-1364.

4 Forbes LJ, Kapetanakis V, Rudnicka AR, et al. Chronic exposure to outdoor air pollution and lung function in adults. Thorax 2009; 64: 657-663.

5 Ackermann-Liebrich U, Leuenberger P, Schwartz J, et al. Lung function and long term exposure to air pollutants in Switzerland. Study on Air Pollution and Lung Diseases in Adults (SAPALDIA) Team. Am J Respir Crit Care Med 1997; 155: 122-129.

6 Gotschi T, Heinrich J, Sunyer J, et al. Long-term effects of ambient air pollution on lung function: a review. Epidemiology (Cambridge, Mass) 2008; 19: 690-701.

7 Schikowski T, Sugiri D, Ranft U, et al. Long-term air pollution exposure and living close to busy roads are associated with COPD in women. Respir Res 2005; 6: 152.

8 Downs SH, Schindler C, Liu LJ, et al. Reduced exposure to PM10 and attenuated age-related decline in lung function. N Engl J Med 2007; 357: 2338-2347.

9 Eckel SP, Louis TA, Chaves $\mathrm{PH}$, et al. Modification of the association between ambient air pollution and lung function by frailty status among older adults in the Cardiovascular Health Study. Am J Epidemiol 2012; 176: 214-223.

10 Eeftens M, Beelen R, de Hoogh K, et al. Development of Land Use Regression models for PM2.5, PM2.5 absorbance, PM10 and PMcoarse in 20 European study areas; results of the ESCAPE project. Environ Sci Technol 2012; 46: 11195-11205.

11 Beelen $\mathrm{R}$, Hoek G, Vienneau $\mathrm{D}$, et al. Development of $\mathrm{NO}_{2}$ and $\mathrm{NO}_{\mathrm{x}}$ land use regression models for estimating air pollution exposure in 36 study areas in Europe - The ESCAPE project. Atmos Environ 2013; 72: 10-23.

12 Beelen R, Raaschou-Nielsen O, Stafoggia M, et al. Effects of long-term exposure to air pollution on natural-cause mortality: an analysis of 22 European cohorts within the multicentre ESCAPE project. Lancet 2014; 383: 785-795.

13 Eeftens M, Tsai MY, Ampe C, et al. Spatial variation of PM2.5, PM10, PM2.5 absorbance and PMcoarse concentrations between and within 20 European study areas and the relationship with $\mathrm{NO}_{2}$ - Results of the ESCAPE project. Atmos Environ 2012; 62: 303-317.

14 Cyrys J, Eeftens $\mathrm{M}$, Heinrich J, et al. Variation of $\mathrm{NO}_{2}$ and $\mathrm{NO}_{\mathrm{x}}$ concentrations between and within 36 European study areas: results from the ESCAPE study. Atmos Environ 2012; 62: 374-390.

15 Gulliver J, de Hoogh K, Hansell A, et al. Development and back-extrapolation of $\mathrm{NO}_{2}$ land use regression models for historic exposure assessment in Great Britain. Environ Sci Technol 2013; 47: 7804-7811.

16 Young RP, Hopkins R, Eaton TE. Forced expiratory volume in one second: not just a lung function test but a marker of premature death from all causes. Eur Respir J 2007; 30: 616-622.

17 Schikowski T, Schaffner E, Meier F, et al. Improved air quality and attenuated lung function decline: modification by obesity in the SAPALDIA cohort. Environ Health Perspect 2013; 121: 1034-1039.

18 Jones RL, Nzekwu MM. The effects of body mass index on lung volumes. Chest 2006; 130: 827-833.

19 Pistelli F, Bottai M, Carrozzi L, et al. Changes in obesity status and lung function decline in a general population sample. Respir Med 2008; 102: 674-680.

20 Mancuso P. Obesity and lung inflammation. J Appl Physiol 2010; 108: 722-728.

21 Dubowsky SD, Suh H, Schwartz J, et al. Diabetes, obesity, and hypertension may enhance associations between air pollution and markers of systemic inflammation. Environ Health Perspect 2006; 114: 992-998.

22 Madrigano J, Baccarelli A, Wright RO, et al. Air pollution, obesity, genes and cellular adhesion molecules. Occup Environ Med 2010; 67: 312-317.

23 Johnston RA, Theman TA, Lu FL, et al. Diet-induced obesity causes innate airway hyperresponsiveness to methacholine and enhances ozone-induced pulmonary inflammation. J Appl Physiol 2008; 104: 1727-1735.

24 Shore SA, Lang JE, Kasahara DI, et al. Pulmonary responses to subacute ozone exposure in obese vs. lean mice. J Appl Physiol 2009; 107: 1445-1452.

25 Alexeeff SE, Litonjua AA, Suh H, et al. Ozone exposure and lung function: effect modified by obesity and airways hyperresponsiveness in the VA normative aging study. Chest 2007; 132: 1890-1897. 
26 Bennett WD, Hazucha MJ, Folinsbee LJ, et al. Acute pulmonary function response to ozone in young adults as a function of body mass index. Inhal Toxicol 2007; 19: 1147-1154.

27 Gotschi T, Sunyer J, Chinn S, et al. Air pollution and lung function in the European Community Respiratory Health Survey. Int J Epidemiol 2008; 37: 1349-1358.

28 Gerbase MW, Dupuis-Lozeron E, Schindler C, et al. Agreement between spirometers: a challenge in the follow-up of patients and populations?. Respiration 2013; 85: 505-514.

29 Basagana X, Rivera M, Aguilera I, et al. Effect of the number of measurement sites on land use regression models in estimating local air pollution. Atmos Environ 2012; 54: 634-642.

30 Wang M, Beelen R, Eeftens M, et al. Systematic Evaluation of land use regression models for $\mathrm{NO}_{2}$. Environ Sci Technol 2012; 46: 4481-4489. 